\title{
Folate intake and breast cancer mortality in a cohort of Swedish women
}

\author{
Holly R. Harris, \\ Division of Nutritional Epidemiology, The National Institute for Environmental Medicine, \\ Karolinska Institutet, P.O. Box 210, SE 17177 Stockholm, Sweden. Obstetrics and Gynecology \\ Epidemiology Center, Brigham and Women's Hospital, 221 Longwood Avenue, Boston, MA, USA \\ 02115
}

Leif Bergkvist, and

Department of Surgery and Centre for Clinical Research, Central Hospital, 72189 Västerås, Sweden

\author{
Alicja Wolk \\ Division of Nutritional Epidemiology, The National Institute for Environmental Medicine, \\ Karolinska Institutet, P.O. Box 210, SE 17177 Stockholm, Sweden \\ Holly R. Harris: holly.harris@ki.se
}

\begin{abstract}
Folate may influence breast cancer development and progression through its role in one-carbon metabolism. However, epidemiologic data on the relation between folate and breast cancer survival are limited. We investigated whether dietary folate intake was associated with survival in 3,116 women diagnosed with breast cancer in the population-based Swedish Mammography Cohort. Participants completed a 67-item food frequency questionnaire in 1987. Cox proportional hazard models were used to calculate hazard ratios (HRs) and 95\% confidence intervals (95\% CIs) for death from breast cancer and death from any cause. During 25,716 person-years of follow-up from 1987 to 2008, there were 852 deaths with 381 breast cancer deaths. Dietary folate intake was inversely associated with breast cancer and overall mortality. Women in the highest quartile of folate intake had a multivariable HR $(95 \% \mathrm{CI})$ of death from breast cancer of $0.78(0.58-1.03)$ compared to those in the lowest quartile $\left(P_{\text {trend }}=0.03\right)$. The corresponding HR $(95 \% \mathrm{CI})$ for death from any cause was $0.79\left(0.66-0.96 ; P_{\text {trend }}=0.004\right)$. The protective association between dietary folate intake and breast cancer death was strongest among those with ER-negative tumors (HR = $0.42 ; 95 \%=$ CI $\left.0.22-0.79 ; P_{\text {trend }}=0.01\right)$ comparing the highest to lowest quartile. Our findings suggest that folate intake before breast cancer diagnosis may improve breast cancer and overall survival. While these findings need to be confirmed in future studies, they do offer assurance that dietary folate intake at the levels observed in our population does not unfavorably affect survival after breast cancer.
\end{abstract}

\section{Keywords}

Breast cancer; Survival; Folate; Diet

(C) Springer Science+Business Media, LLC. 2011

Correspondence to: Holly R. Harris, holly . harriseki.se.

Conflicts of interest None. 


\section{Introduction}

The association between dietary factors and the development of breast cancer has been extensively studied, but less is known about how dietary factors may influence breast cancer survival. Previous observational studies of diet and mortality among women with breast cancer have primarily examined macronutrients, reporting inconsistent results [1].

Folate, a water-soluble B vitamin, has been hypothesized to influence breast cancer development and progression through its role in one-carbon metabolism. Inadequate folate intake may lead to disturbances in the one-carbon metabolism pathway causing alterations in DNA and RNA methylation as well as disruption in DNA integrity and repair [2], all of which are critical factors in carcinogenesis and may influence cancer survival. However, to our knowledge, breast cancer-specific survival in relation to folate intake has been examined only as a secondary endpoint with these studies reporting that a higher dietary folate intake was associated with a non-significant decreased risk of breast cancer-specific mortality [35]. No studies have explored whether the association between folate intake and breast cancer-specific survival is modified by hormone receptor status. The primary endpoint in previous studies examining folate intake and survival among breast cancer patients has been all-cause mortality [3-7]. The majority of these studies have reported a non-significant inverse association between folate, measured both pre- and postdiagnosis and all-cause mortality $[3,5,7]$, while one study reported a significant inverse association between prediagnostic dietary folate and all-cause mortality [4].

The aim of this study was to investigate whether pre-diagnosis dietary folate intake was associated with breast cancer-specific mortality and all-cause mortality among women diagnosed with invasive breast cancer in the population-based Swedish Mammography Cohort (SMC). We also examined whether the association between folate and survival differed by hormone receptor status, alcohol consumption, body mass index (BMI), and disease stage at diagnosis.

\section{Materials and methods}

\section{Study population}

This study included 3,116 participants in the Swedish Mammography Cohort with invasive breast cancer diagnosed from 1987 to 2008. Recruitment and characteristics of this cohort have been previously described [8]. In brief, the SMC is a population-based cohort of 66,651 women born between 1914 and 1948 that were recruited between 1987 and 1990 in Västmanland and Uppsala counties in central Sweden. Participants completed a baseline questionnaire with questions regarding diet, reproductive and other factors. In 1997, a second questionnaire was extended to include dietary supplements and physical activity and was sent to participants who were still alive and residing in the study area; 39,227 (70\%) women returned this questionnaire. Those with an incorrect or missing national registration number, previous cancer diagnosis (except non-melanoma skin cancer) and implausible total energy intake (3 standard deviations [SD] from the mean value for $\log _{\mathrm{e}}$-transformed energy intake) were excluded from the baseline cohort. Completion and return of the selfadministered questionnaire were treated as informed consent of study participants. The study was approved by the ethics committees at the Uppsala University Hospital and the Karolinska Institutet.

Histologically confirmed incident invasive breast cancer cases were ascertained by linkage of the study cohort with Swedish Cancer registers. These registers have been estimated to provide almost 100\% complete case ascertainment [9]. Estrogen receptor (ER) and progesterone receptor $(\mathrm{PR})$ status and other clinical characteristics were obtained by 
reviewing pathology laboratory works logs from Uppsala University Hospital and by linking with the clinical database at the Regional Oncology Centre in Uppsala. Estrogen and progesterone receptor status, menopausal status at diagnosis, tumor size, grade, lymph node involvement, and type of treatment were available for approximately $77 \%$ of the cases. More detailed information on the evaluation of hormone receptor status in this cohort has been described previously [10].

\section{Dietary assessment}

Diet was assessed using a 67-item food frequency questionnaire (FFQ) at baseline and a 96item FFQ in 1997. Participants were asked how often, on average, they had consumed each food item or beverage during the previous 6 months (1987) or year (1997). Eight responses were possible, ranging from never or seldom to four or more times per day. Dietary folate intake was calculated as the frequency of consumption of each food item multiplied by its folate content per age-specific serving using food composition values obtained from the Swedish National Food Administration Database [11]. The FFQ has been previously validated among 129 participants with correlation coefficients between the questionnaire and four 1-week dietary records of 0.5 for dietary folate (A Wolk, unpublished data, 1992). Nutrient intakes were adjusted for energy using the residual method [12].

\section{Outcome assessment}

Date of death was identified through linkage to the Swedish National Death Registry at Statistics Sweden. It is estimated that $93 \%$ of all deaths in Sweden are reported within 10 days and $100 \%$ are reported within 30 days [13]. Cause of death was determined by International Classification of Diseases (ICD) codes (ICD9 and ICD10) through linkage to the Cause of Death Registry at the National Bureau of Health and Welfare.

\section{Statistical analysis}

Cox proportional hazard models with time since diagnosis in months as the time scale were used to calculate hazard ratios (HRs) and 95\% confidence intervals (95\% CIs) for death from breast cancer. Participants contributed person-time from the date of breast cancer diagnosis until death from breast cancer (primary endpoint), death from another cause or end of follow-up on December 31, 2008. Secondary analyses were conducted with death from any cause as the endpoint. Baseline diet (1987) was considered the exposure in all analyses except when dietary change was examined. Those with folate intake of $3 \mathrm{SD}$ from the mean value were excluded. Folate intake was categorized in quartiles with the lowest quartile as the reference group. Total caloric intake and age at diagnosis were included in all models.

Education level, marital status, menopausal status at diagnosis, BMI, alcohol intake, and calendar year of diagnosis were considered potential confounders in all multivariable models. Parity, age at first birth, oral contraceptive use, postmenopausal hormone use, height, and family history of breast cancer were not observed to be confounders in the study population and therefore were not included in the final models. Categories were created for missing data. Additional multivariable models were adjusted for the following clinical characteristics: stage, grade, radiation treatment, and chemotherapy/hormonal therapy. Additional adjustment for the clinical covariates tumor size and number of positive lymph nodes did not further alter the effect estimates thus were not included in the final models. Tests for linear trend were performed by assigning the median value of each quartile to each participant in that group. In addition, we used restricted cubic splines to examine the possibility of a non-linear relation between folate intake and mortality.

We examined whether the association between dietary folate and breast cancer survival differed by hormone receptor status, alcohol consumption, BMI, disease stage at diagnosis, 
or time between dietary assessment and breast cancer diagnosis with a likelihood ratio test comparing the model with the cross-product term between folate and each potential effect modifier to the model with main effects only. All tests of statistical significance were twosided, and statistical analyses were performed using SAS Version 9.2 (SAS Institute Inc., Cary, NC) and Stata (StataCorp, College Station, TX).

\section{Results}

During 25,716 person-years of follow-up contributed by 3,116 breast cancer cases, there were 852 deaths with 381 deaths from breast cancer. The mean $( \pm$ SD) age at diagnosis was 65 years ( \pm 10.3 ), and the median follow-up time was 7.3 years (range 1 month-21.8 years). Dietary assessment occured a median of 10.6 years before breast cancer diagnosis (range 1 month-21.8 years).

The mean folate intake was $219 \mu \mathrm{g} / \mathrm{d}( \pm 42)$, slightly lower than the baseline value of 234 $\mu \mathrm{g} / \mathrm{d}( \pm 50)$ observed in the full cohort [14]. The main sources of dietary folate in the study population were bread, leafy green vegetables, and citrus fruits. The distribution of participant characteristics in each quartile of folate intake is shown in Table 1. Breast cancer stage, grade, treatment, tumor size, number of positive lymph nodes, and hormone receptor status were all associated with breast cancer mortality in age-adjusted analyses (results not shown).

Dietary folate intake was associated with a decreased risk of breast cancer death (Table 2). Women in the highest quartile of folate intake had an age- and energy-adjusted HR (95\% CI) of death from breast cancer of $0.72(0.54-0.96)$ compared to those in the lowest quartile $\left(P_{\text {trend }}=0.009\right)$. Adjustment for education level, marital status, menopausal status at diagnosis, body mass index, alcohol intake, and calendar year of diagnosis slightly attenuated the inverse association (HR for top to bottom quartile $=0.76 ; 95 \% \mathrm{CI}=0.57-$ $1.01)$; however, the trend was still significant $\left(P_{\text {trend }}=0.02\right)$. Further adjustment for clinical characteristics (breast cancer stage and grade) and treatment did not alter the results (HR for top to bottom quartile $=0.78 ; 95 \% \mathrm{CI}=0.58-1.03 ; P_{\text {trend }}=0.03$ ). We also observed a reduced risk of death from breast cancer in the third quartile of folate intake. When we examined the association using continuous folate, an increase in intake of folate of $100 \mu \mathrm{g} /$ day was associated with a $23 \%$ reduced risk of death from breast cancer $(95 \%$ CI $0.61-$ $0.99)$. We found no evidence of non-linearity when using restricted cubic splines $(P=0.80)$. Results were similar when death from any cause was the outcome (Table 2).

When the association between dietary folate and breast cancer death was stratified by hormone receptor status of the tumor, the protective association between dietary folate intake and breast cancer death was strongest among those with ER-negative tumors (Table 3). Among women with ER-negative tumors, those in the highest quartile of dietary folate intake had a covariate-adjusted HR of $0.60\left(95 \% \mathrm{CI}=0.33-1.09 ; P_{\text {trend }}=0.09\right)$ and a covariate and clinical characteristics adjusted HR of $0.42\left(95 \% \mathrm{CI}=0.22-0.79 ; P_{\text {trend }}=\right.$ $0.01)$ compared to women in the lowest quartile. The corresponding covariate- and clinical characteristics-adjusted HR for ER-positive breast cancer was 1.04 (95\% CI $=0.66-1.64$; $\left.P_{\text {trend }}=0.59\right)$. However, the $P$-value for heterogeneity was not significant $(P=0.11)$. In addition, no heterogeneity was observed across PR status $\left(P_{\text {heterogeneity }}=0.69\right)$. When numbers permitted, we also examined the data by joint ER/PR receptor status. Dietary folate intake appeared to have a significant inverse association with breast cancer death among women whose tumors lacked both estrogen and progesterone receptors when comparing those in the third quartile to those in the lowest quartile (covariate and clinical characteristics adjusted $\mathrm{HR}$ of $0.34 ; 95 \% \mathrm{CI}=0.15-0.75 ; P_{\text {trend }}=0.07$ ), while no significant association was observed for tumors with both estrogen and progesterone receptors (Table 
3). However, these results were based on small numbers, and no heterogeneity was observed across tumor subtypes $\left(P_{\text {heterogeneity }}=0.27\right)$.

When the data were stratified by quartiles of time between dietary assessment and breast cancer diagnosis, an inverse association was observed between dietary folate intake and breast cancer death for all quartiles except for the first quartile ( $0-<4.9$ years) where no association was observed; however, the test for heterogeneity was not significant. The association between dietary folate intake and breast cancer death among all cases did not vary according to alcohol intake, BMI, or stage at diagnosis. In a sensitivity analysis that excluded women with stage IV breast cancer, results were not materially different than the main analysis (results not shown). We also adjusted for physical activity in the subset of women who completed the 1997 questionnaire and saw no change in the effect estimates.

We examined dietary change following breast cancer diagnosis among the 717 breast cancer cases who were diagnosed with breast cancer from 1987 to 1996 and completed an FFQ in 1997 after their breast cancer diagnosis. Over 75\% of these women remained in the same or adjacent quartile of folate intake following breast cancer diagnosis and $25 \%$ reported the use of multivitamins which was identical to multivitamin use observed in the full cohort [15]. Among this subset of women, there were 184 total deaths and 62 breast cancer deaths. Those in the highest quartile of postdiagnosis folate intake had a covariate-adjusted hazard ratio HR $(95 \%$ CI) of death from any cause of $0.75(0.50-1.14)$ compared to those in the lowest quartile $\left(P_{\text {trend }}=0.17\right)$. When breast cancer-specific mortality was examined, the corresponding HR $(95 \% \mathrm{CI})$ was $0.83\left(0.39-1.78 ; P_{\text {trend }}=0.64\right)$; however, these results were based on small numbers.

\section{Discussion}

In this prospective study among 3,116 women with breast cancer, dietary folate intake was inversely associated with breast cancer-specific and overall mortality. In addition, the protective association between dietary folate intake and breast cancer death was strongest among those with ER-negative tumors.

Few epidemiologic studies have explored the relation between dietary folate intake and allcause and breast cancer-specific mortality, and to our knowledge, none have examined the association by hormone receptor status. Overall, most previous studies have shown a suggestion of an inverse association between dietary folate and all-cause mortality and breast cancer-specific mortality. Three studies have examined pre-diagnosis dietary intake $[4,5,7]$ and two examined postdiagnosis intake $[3,6]$. Our results regarding total mortality are most consistent with a small study in Orange County, California, which observed a statistically significant inverse association between dietary folate intake assessed 1 year prior to breast cancer diagnosis and all-cause mortality $(n=96$ total deaths; RR for the third vs. first tertile $=0.34 ; 95 \% \mathrm{CI}=0.18-0.67 ; P_{\text {trend }}=0.0006$ ), but no association with total intake (including folic acid from supplements). The authors reported similar, but nonsignificant, associations with breast cancer-specific mortality but had limited power with only 41 breast cancer deaths [4]. In the Long Island Breast Cancer Study Project, dietary folate assessed in the year before the interview (primarily prediagnostic) was nonsignificantly inversely associated with breast cancer-specific mortality $(n=124$ breast deaths; RR for high vs. low intake $\left.=0.81 ; 95 \% \mathrm{CI}=0.47-1.39 ; P_{\text {trend }}=0.44\right)$ and with allcause mortality $(n=198$ total deaths; RR for high vs. low intake $=0.79$; $95 \% \mathrm{CI}=0.52-$ $\left.1.12 ; P_{\text {trend }}=0.28\right)$ [5]. Among women who received chemotherapy as first course of treatment in the Iowa Women's Health Study, dietary folate was also non-significantly inversely associated with all-cause mortality ( $n=80$ total deaths; RR for third vs. first tertile $=0.85 ; 95 \% \mathrm{CI}=0.38-1.91)$ and a comparable association was observed with total folate 
[7]. Similarly, the Nurses' Health Study, which examined postdiagnosis dietary and total folate intake, reported a non-significant inverse association between total mortality and dietary folate intake ( $n=378$ total deaths; RR for fifth vs. first quintile $=0.82 ; 95 \% \mathrm{CI}=$ $\left.0.59-1.14 ; P_{\text {trend }}=0.43\right)$ and a similar association with total folate. In addition, they reported that breast-cancer-specific mortality results were substantively the same [3]. Most recently, Saquib et al. [6] reported that among women with breast cancer total folate intake above the recommended upper limit was not significantly associated with lower overall mortality. However, many of the studies may have been underpowered to detect a statistically significant association. We had twice as many total deaths as well as more breast cancer deaths than any of the previous studies providing us with ample power to examine these associations between all breast cancer cases as well as separately by subtypes of breast cancer defined by hormone receptor status.

Folate has been hypothesized to influence carcinogenesis through its role in the one-carbon metabolism pathway. Diets low in folate may result in impaired DNA biosynthesis and methylation which can result in proto-oncogene activation as well as chromosome rearrangement and instability, all of which may promote cancer development [16]. The role folate plays in cancer progression is less clear. Studies in animal models of colorectal cancer have demonstrated that high levels of folate supplementation may promote the growth of existing tumors because when neoplastic cell division is occurring at rapid rate low levels of folate may cause ineffective DNA synthesis and thus reduced tumor growth [17, 18]. However, in rats with MNU-induced mammary tumorigenesis, Kotsopoulos et al. [19] reported that while dietary folate deficiency suppressed the progression of established tumors, dietary folate supplementation did not promote the progression of these tumors. In contrast, we observed a decreased risk of breast cancer-specific and overall mortality with increasing dietary folate intake. The average folate level in our population was low $(219 \mu \mathrm{g} /$ d) which did not allow us to examine the folate intake at the levels that are hypothesized to promote tumorigenesis. In addition, in our primary analyses, folate intake was measured prediagnosis so we cannot rule out the possibility that the timing of the measurement may have influenced our results. In individuals not exposed to population-wide folic acid supplementation, as in our study population, the major sources of dietary folate include leafy green vegetables and citrus fruits. Thus, higher folate intakes in non-supplemented populations may be an indicator of an overall healthy diet and lifestyle which itself could impact survival.

The association between folate intake and the development of ER-positive and ER-negative tumors has been inconclusive [14, 20-23], and to our knowledge, we are the first to examine whether the association between folate intake and survival differed by hormone receptor status. We observed that the association between dietary folate and breast cancer survival varied by hormone receptor subtype with the strongest inverse association between women with ER-negative tumors, although the p-value for heterogeneity did not reach statistical significance. These results are in contrast to laboratory studies which have demonstrated that the demethylation of the estrogen receptor gene can reactivate estrogen receptor gene expression in ER-negative breast cancer cells [24, 25]. We may have observed a stronger inverse association with dietary folate and breast cancer survival because ER-negative tumors are less responsive to hormonal therapies, and as a result, the influence of dietary factors on their progression may be more evident than for ER-positive tumors.

Limitations of our study need to be considered. First, for the majority of our participants, we only had a pre-diagnosis assessment of diet and thus had limited power to examine diet postdiagnosis during the follow-up period. Studies have shown that 30-40\% of women report dietary changes following a breast cancer diagnosis, with the main changes being a decrease in meat intake and an increase in fruit and vegetable consumption [26, 27]. 
However, younger women were most likely to report these changes, and the average age at breast cancer diagnosis in our cohort was 65.1 years. In our study, $75 \%$ of women who completed an FFQ postdiagnosis remained in the same or adjacent quartile of folate intake following diagnosis. In addition, we were unable to calculate total folate intake in our population and supplement information was not available at baseline.

Dietary intake was assessed by participants using a self-administered FFQ and was subject to measurement error. However, the FFQ has been previously validated with diet records with correlations of 0.5 for dietary folate (A Wolk, unpublished data, 1992). We expect that the errors in dietary assessment would likely cause an attenuation of the true effect. Additionally, residual or unmeasured confounding by physical activity or other dietary factors is a possibility. However, we adjusted for physical activity in the subset of breast cancer cases with this information and the association did not materially change.

Our study has several strengths. To our knowledge, this is the largest study to examine the association between dietary folate intake and mortality with 860 total deaths including 385 breast cancer deaths, which allowed us the power to examine breast cancer-specific mortality as well as how the association differed by tumor hormone receptor status. Strengths also include a prospective population-based cohort, nearly complete follow-up of all cases, long follow-up period, detailed information on diet, and data on many important covariates, including clinical and lifestyle characteristics.

In conclusion, our findings suggest that folate intake before breast cancer diagnosis may improve breast cancer and overall survival. While these findings need to be con-firmed in future studies, they do offer assurance that dietary folate intake at the levels observed in our population does not unfavorably affect survival after breast cancer.

\section{Acknowledgments}

This study was supported by the Swedish Cancer Foundation, the Swedish Research Council/Committee for Infrastructure, and the Swedish Foundation for International Cooperation in Research and Higher Education. H.R.H. was supported by NIH training grant T32 ES007069 and MCHB grant 5T76MC00001 (formerly MCJ201).

\section{Abbreviations}

$\begin{array}{ll}\text { SMC } & \text { Swedish mammography cohort } \\ \text { BMI } & \text { Body mass index } \\ \text { SD } & \text { Standard deviation } \\ \text { ER } & \text { Estrogen receptor } \\ \text { PR } & \text { Progesterone receptor } \\ \text { FFQ } & \text { Food frequency questionnaire } \\ \text { ICD } & \text { International classification of diseases } \\ \text { HR } & \text { Hazard ratio } \\ \text { CI } & \text { Confidence interval }\end{array}$

\section{References}

1. Patterson RE, Cadmus LA, Emond JA, Pierce JP. Physical activity, diet, adiposity and female breast cancer prognosis: a review of the epidemiologic literature. Maturitas. 2010; 66(1):5-15. [PubMed: 20097494] 
2. Mason JB, Choi S-W. Folate and carcinogenesis: developing a unifying hypothesis. Adv Enzyme Regul. 2000; 40(1):127-141. [PubMed: 10828349]

3. Holmes MD, Stampfer MJ, Colditz GA, Rosner B, Hunter DJ, Willett WC. Dietary factors and the survival of women with breast carcinoma. Cancer. 1999; 86(5):826-835. [PubMed: 10463982]

4. McEligot A, Largent J, Ziogas A, Peel D, Anton-Culver H. Dietary fat, fiber, vegetable, and micronutrients are associated with overall survival in postmenopausal women diagnosed with breast cancer. Nutr Cancer. 2006; 55(2):132-140. [PubMed: 17044767]

5. Xu X, Gammon MD, Wetmur JG, Bradshaw PT, Teitelbaum SL, Neugut AI, Santella RM, Chen J. B-vitamin intake, one-carbon metabolism, and survival in a population-based study of women with breast cancer. Cancer Epidemiol Biomarkers Prev. 2008; 17(8):2109-2116. [PubMed: 18708404]

6. Saquib J, Rock CL, Natarajan L, Saquib N, Newman VA, Patterson RE, Thomson CA, Al-Delaimy WK, Pierce JP. Dietary intake, supplement use, and survival among women diagnosed with earlystage breast cancer. Nutr Cancer. 2011; 63(3):327-333. [PubMed: 21391124]

7. Sellers TA, Alberts SR, Vierkant RA, Grabrick DM, Cerhan JR, Vachon CM, Olson JE, Kushi LH, Potter JD. High-folate diets and breast cancer survival in a prospective cohort study. Nutr Cancer. 2002; 44(2):139-144. [PubMed: 12734059]

8. Wolk A, Larsson SC, Johansson J-E, Ekman P. Long-term fatty fish consumption and renal cell carcinoma incidence in women. JAMA. 2006; 296(11):1371-1376. [PubMed: 16985229]

9. Mattsson B, Wallgren A. Completeness of the Swedish Cancer Register. Non-notified cancer cases recorded on death certificates in 1978. Acta Radiol Oncol. 1984; 23:305-313. [PubMed: 6095600]

10. Larsson SC, Bergkvist L, Wolk A. Long-term meat intake and risk of breast cancer by oestrogen and progesterone receptor status in a cohort of Swedish women. Eur J Cancer. 2009; 45(17):30423046. [PubMed: 19464165]

11. Bergström L, Kylberg E, Hagman U, Erikson H, Bruce A. The food composition database KOST: the National Food Administration's Information System for nutritive values of food. Vår Fö da. 1991; 43:439-447.

12. Willett W, Stampfer MJ. Total energy intake: implications for epidemiologic analyses. Am J Epidemiol. 1986; 124(1):17-27. [PubMed: 3521261]

13. Ludvigsson J, Otterblad-Olausson P, Pettersson B, Ekbom A. The Swedish personal identity number: possibilities and pitfalls in healthcare and medical research. Eur J Epidemiol. 2009; 24(11):659-667. [PubMed: 19504049]

14. Larsson SC, Bergkvist L, Wolk A. Folate intake and risk of breast cancer by estrogen and progesterone receptor status in a Swedish cohort. Cancer Epidemiol Biomarkers Prev. 2008; 17(12):3444-3449. [PubMed: 19064560]

15. Larsson SC, Åkesson A, Bergkvist L, Wolk A. Multivitamin use and breast cancer incidence in a prospective cohort of Swedish women. Am J Clin Nutr. 2010; 91(5):1268-1272. [PubMed: 20335555]

16. Lamprecht SA, Lipkin M. Chemoprevention of colon cancer by calcium, vitamin D and folate: molecular mechanisms. Nat Rev Cancer. 2003; 3(8):601-614. [PubMed: 12894248]

17. Kim Y-I. Role of folate in colon cancer development and progression. J Nutr. 2003; 133(11): 3731S-3739S. [PubMed: 14608107]

18. Kim Y-I. Folate: a magic bullet or a double edged sword for colorectal cancer prevention? Gut. 2006; 55(10):1387-1389. [PubMed: 16966698]

19. Kotsopoulos J, Medline A, Renlund R, Sohn K-J, Martin R, Hwang SW, Lu S, Archer MC, Kim Y-I. Effects of dietary folate on the development and progression of mammary tumors in rats. Carcinogenesis. 2005; 26(9):1603-1612. [PubMed: 15888495]

20. Cho E, Holmes M, Hankinson SE, Willett WC. Nutrients involved in one-carbon metabolism and risk of breast cancer among premenopausal women. Cancer Epidemiol Biomarkers Prev. 2007; 16(12):2787-2790. [PubMed: 18086790]

21. Lin J, Lee I-M, Cook NR, Selhub J, Manson JE, Buring JE, Zhang SM. Plasma folate, vitamin B-6, vitamin B-12, and risk of breast cancer in women. Am J Clin Nutr. 2008; 87(3):734-743. [PubMed: 18326613]

22. Sellers TA, Vierkant RA, Cerhan JR, Gapstur SM, Vachon CM, Olson JE, Pankratz VS, Kushi LH, Folsom AR. Interaction of dietary folate intake, alcohol, and risk of hormone receptor-defined 
breast cancer in a prospective study of postmenopausal women. Cancer Epidemiol Biomarkers Prev. 2002; 11(10):1104-1107. [PubMed: 12376515]

23. Zhang SM, Hankinson SE, Hunter DJ, Giovannucci EL, Colditz GA, Willett WC. Folate intake and risk of breast cancer characterized by hormone receptor status. Cancer Epidemiol Biomarkers Prev. 2005; 14(8):2004-2008. [PubMed: 16103452]

24. Ferguson AT, Lapidus RG, Baylin SB, Davidson NE. Demethylation of the estrogen receptor gene in estrogen receptor-negative breast cancer cells can reactivate estrogen receptor gene expression. Cancer Res. 1995; 55(11):2279-2283. [PubMed: 7538900]

25. Lapidus RG, Nass SJ, Butash KA, Parl FF, Weitzman SA, Graff JG, Herman JG, Davidson NE. Mapping of ER gene CpG island methylation by methylation-specific polymerase chain reaction. Cancer Res. 1998; 58(12):2515-2519. [PubMed: 9635570]

26. Maunsell E, Drolet M, Brisson J, Robert J, Deschênes L. Dietary change after breast cancer: extent, predictors, and relation with psychological distress. J Clin Oncol. 2002; 20(4):1017-1025. [PubMed: 11844825]

27. Salminen EK, Lagstrom HK. Does breast cancer change patients' dietary habits? Eur J Clin Nutr. 2000; 54(11):844. [PubMed: 11114679] 
Table 1

Characteristics of 3,116 women with invasive breast cancer in the Swedish mammography cohort by quartiles of dietary folate intake ${ }^{a}$

\begin{tabular}{|c|c|c|c|c|}
\hline & \multicolumn{4}{|c|}{ Quartile of folate intake $(\mu \mathrm{g} / \mathrm{d})$} \\
\hline & $<190$ & 190-217 & 218-245 & $\geq 246$ \\
\hline Median folate intake $(\mu \mathrm{g} / \mathrm{d})$ & 162.2 & 203.0 & 225.4 & 259.7 \\
\hline Age at enrollment (years) & 53.0 & 52.6 & 53.1 & 53.8 \\
\hline Age at diagnosis (years) & 65.1 & 64.5 & 65.1 & 65.8 \\
\hline Postsecondary education (\%) & $8.9 \%$ & $11.3 \%$ & $11.4 \%$ & $16.9 \%$ \\
\hline Married (\%) & $69.1 \%$ & $75.4 \%$ & $70.9 \%$ & $66.4 \%$ \\
\hline Body mass index $\left(\mathrm{kg} / \mathrm{m}^{2}\right)$ & 24.9 & 24.9 & 25.1 & 25.0 \\
\hline Height $(\mathrm{cm})$ & 164.7 & 164.7 & 164.6 & 164.4 \\
\hline Age at menarche (years) & 13.3 & 13.3 & 13.1 & 13.2 \\
\hline Nulliparous (\%) & $12.7 \%$ & $13.6 \%$ & $13.1 \%$ & $12.6 \%$ \\
\hline Age at first birth among parous women (years) & 24.3 & 24.5 & 24.8 & 25.0 \\
\hline Number of children & 2.3 & 2.2 & 2.3 & 2.3 \\
\hline Family history of breast cancer $(\%)$ & $8.5 \%$ & $13.1 \%$ & $11.2 \%$ & $11.8 \%$ \\
\hline Ever use of oral contraceptives (\%) & $55.7 \%$ & $57.8 \%$ & $53.1 \%$ & $55.0 \%$ \\
\hline Ever use of postmenopausal hormones (\%) & $42.1 \%$ & $46.3 \%$ & $45.7 \%$ & $49.5 \%$ \\
\hline Postmenopausal at diagnosis (\%) & $90.1 \%$ & $90.9 \%$ & $89.6 \%$ & $91.9 \%$ \\
\hline Alcohol intake $(\mathrm{g} / \mathrm{d})$ & 2.8 & 3.1 & 2.6 & 2.6 \\
\hline Total energy intake (kcal/d) & 1565 & 1634 & 1599 & 1551 \\
\hline \multicolumn{5}{|l|}{ Disease stage $(\%)^{b}$} \\
\hline Stage I & $54.3 \%$ & $48.2 \%$ & $51.5 \%$ & $53.8 \%$ \\
\hline Stage II & $38.3 \%$ & $44.1 \%$ & $41.3 \%$ & $39.7 \%$ \\
\hline Stage III/IV & $6.4 \%$ & $5.6 \%$ & $5.3 \%$ & $5.0 \%$ \\
\hline \multicolumn{5}{|l|}{ Treatment $(\%)^{c}$} \\
\hline Radiation & $56.4 \%$ & $57.0 \%$ & $56.1 \%$ & $56.4 \%$ \\
\hline Chemotherapy & $15.8 \%$ & $17.6 \%$ & $14.1 \%$ & $13.5 \%$ \\
\hline Hormonal & $35.6 \%$ & $33.8 \%$ & $33.9 \%$ & $36.6 \%$ \\
\hline Estrogen receptor positive (\%) & $82.8 \%$ & $81.4 \%$ & $80.5 \%$ & $82.7 \%$ \\
\hline Progesterone receptor positive (\%) & $65.0 \%$ & $65.4 \%$ & $68.7 \%$ & $69.0 \%$ \\
\hline
\end{tabular}




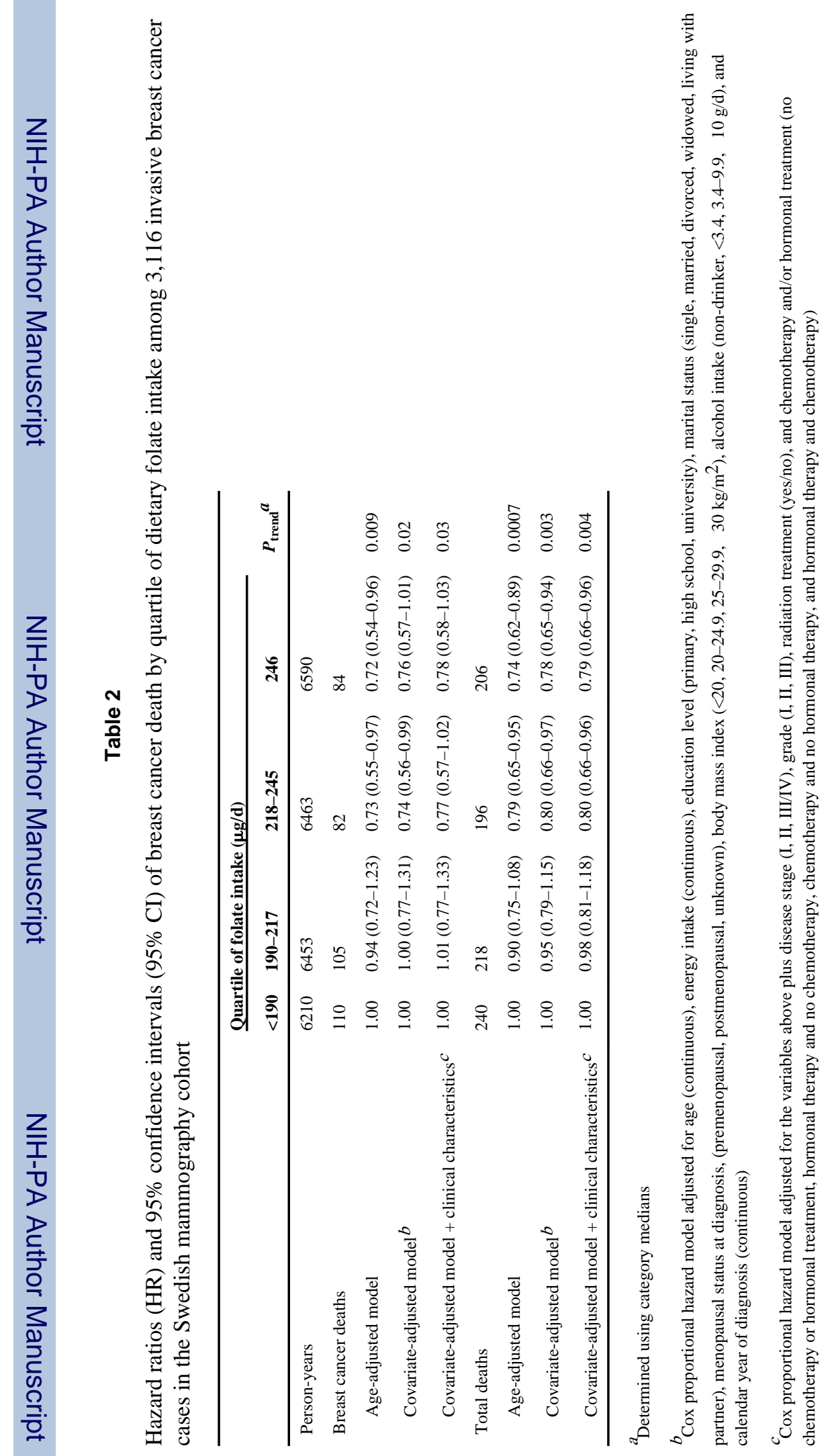




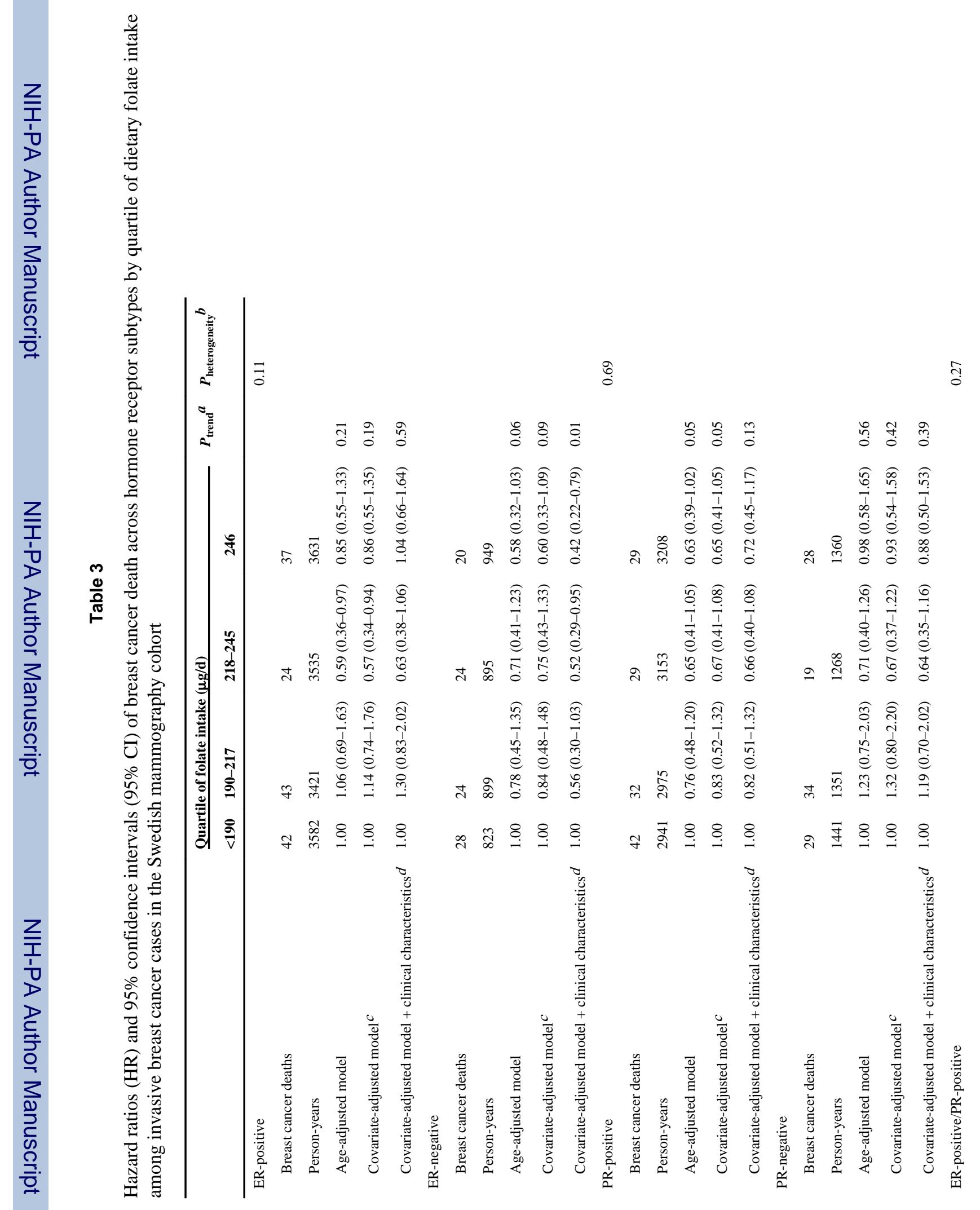




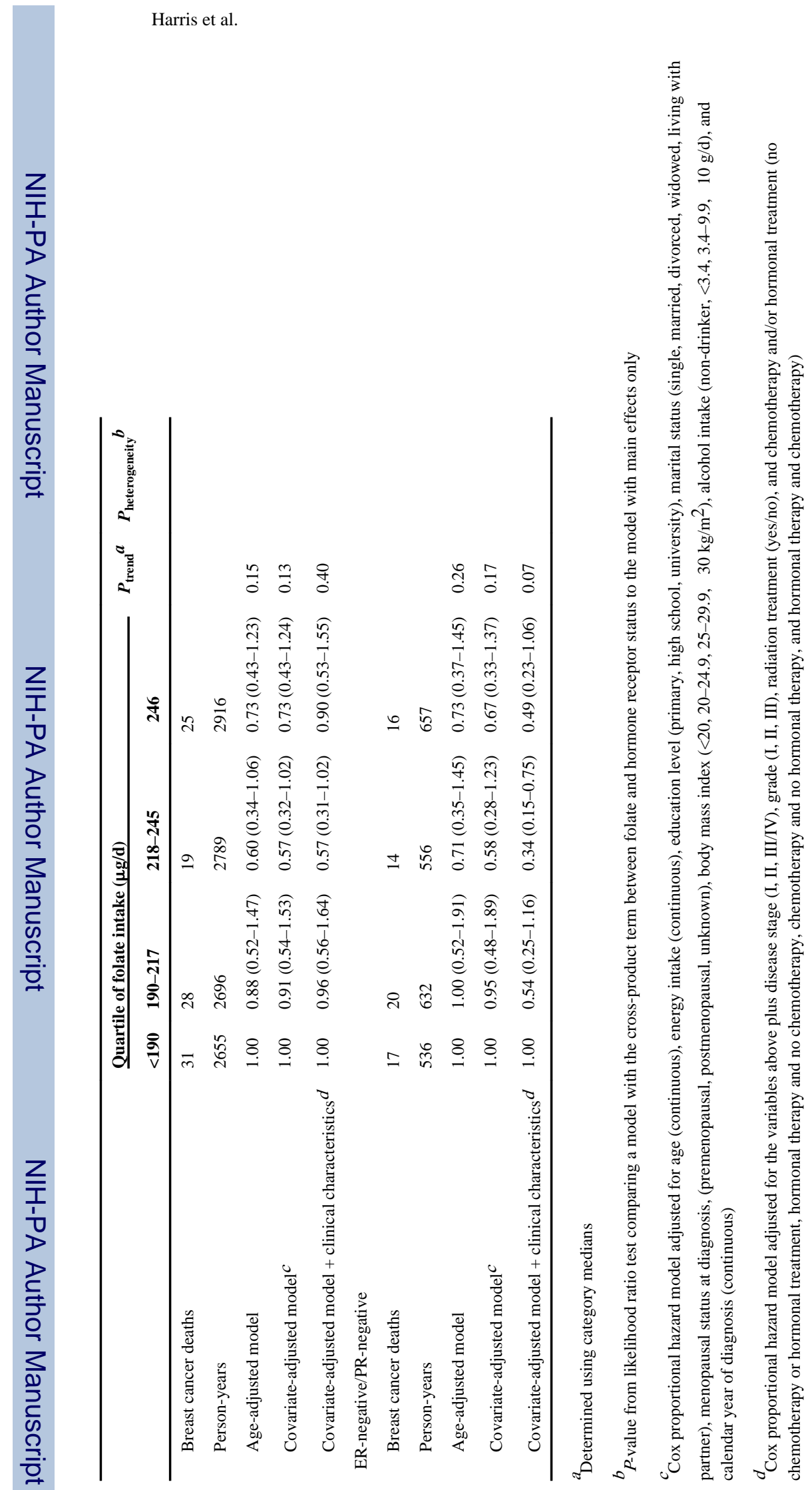

Breast Cancer Res Treat. Author manuscript; available in PMC 2013 August 20. 